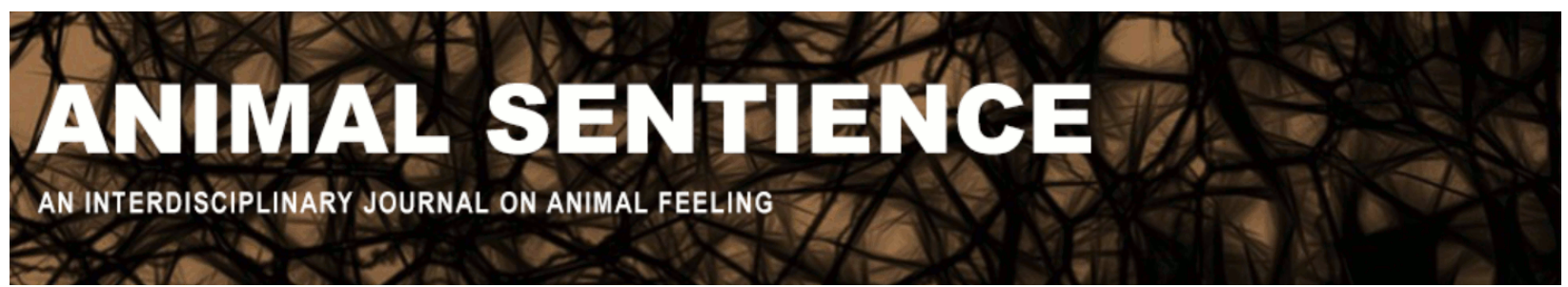

Wallach, Arian D.; Jasinghe, Sujeewa; Fernando, Sudarshani; and Rizzolo, Jessica Bell (2020) Compassionate conservation and elephant personhood. Animal Sentience 28(16)

DOI: $10.51291 / 2377-7478.1576$

Date of submission: $2020-04-16$

Date of acceptance: 2020-04-23

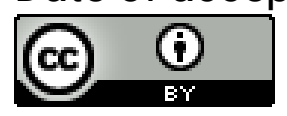




\title{
Compassionate conservation and elephant personhood
}

Commentary on Baker \& Winkler on Elephant Rewilding

\author{
Arian D. Wallach ${ }^{1}$, Sujeewa Jasinghe ${ }^{2}$, Sudarshani Fernando ${ }^{2}$ \& Jessica Bell Rizzolo ${ }^{3}$ \\ ${ }^{1}$ Centre for Compassionate Conservation, University of Technology, Sydney \\ ${ }^{2}$ Centre for Eco-Cultural Studies, Diyakapilla, Sigiriya, Sri Lanka \\ ${ }^{3}$ Conservation Criminology Laboratory, Michigan State University
}

\begin{abstract}
Baker and Winkler (2020) advocate a rehabilitation program that would end the oppression of elephants - not by severing human-elephant relations, but by enabling humanbonded elephants to live a full life. We consider this program within a compassionate conservation framework, which recognises all sentient beings as persons. From this vantage point, we gaze further into the future to ask what direction just human-elephant relations could take: What could emerge from a human-elephant relation once elephants are no longer enslaved and requiring rescue? We envisage a future - beyond captivity and rewilding - of elephant sovereignty.
\end{abstract}

Arian Wallach is an ecologist working to promote compassionate approaches to conservation that enable the persistence of species and respect the lives of individual wild animals. Website

Sujeewa Jasinghe is a resident environmental specialist, archaeozoologist, and co-founder of the Centre for EcoCultural Studies. Website
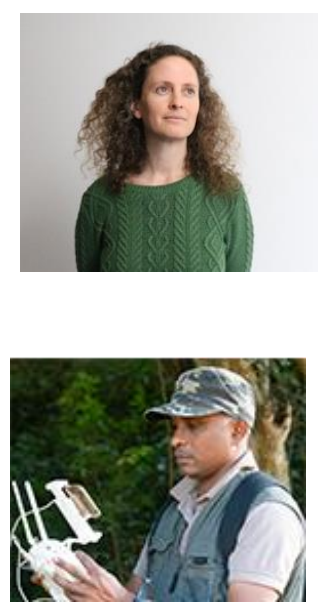

Sudarshani Fernando is a resident anthropologist and cofounder of the Centre for Eco-Cultural Studies engaged in community participatory conservation initiatives with forest people jointly combating illegal captivity of wild elephants and sloth bears, through legal prosecutions. Website

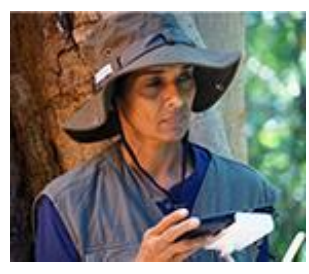

Jessica Bell Rizzolo, postdoctoral researcher at the Conservation Criminology Laboratory at Michigan State University, does research on human-animal interaction and trans-species psychology in the context of tourism and the wildlife trade. Website

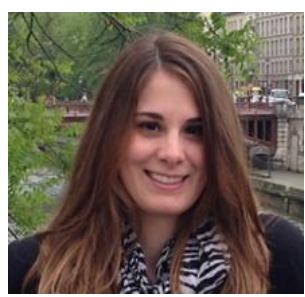


The captive elephant has long been prized as "an object of worship ... a beast of burden...the pride of kings, the companion of mahouts, a machine of war, an envoy of peace..." (Sukumar 1992). Today's human-elephant relation continues this well-trodden human-centric path. Elephants are the prize of the tourism industry, which holds most of the world's elephants captive.

Baker \& Winkler (2020) (B\&W) join calls to start a new trajectory. They advocate a rehabilitation program which would end the oppression of elephants - not by severing elephants from humans, but by enabling human-bonded elephants to live full lives. The program aims to transform the tourism industry from exploiter of elephants to fosterer of human-elephant reciprocity. We consider how this forward-looking program could lead to the recognition of animal personhood, and - eventually - sovereignty.

Elephant persons. Compassionate conservation takes the standpoint that all sentient beings should be recognised as persons (Wallach et al. 2020a). A person, in an ethical sense, is someone (rather than something) whose moral status is respected. Currently, only humans are widely regarded as persons, while all other beings, including those with emotional, mental, and social sophistication, such as elephants, are excluded from this moral community. Wild elephants are regarded as units of Elephas maximus, while captive elephants are treated as property. Recognising other animals as persons would be, for most current societies, revolutionary. It will take an elephant to break through the immutable human-animal barrier.

Elephants provide one of the strongest justifications for extending personhood beyond humans. Elephant beings are not only sentient, but are "psychological beings": those for whom mental, emotional, and social conditions determine their ability to thrive (Rizzolo \& Bradshaw 2019). Rewilding involves not only the absence of cruelty, but also the presence of physical and psychological flourishing and agency (Rizzolo \& Bradshaw 2019). Currently, alongside physical deprivations, the tourism industry creates conditions of such psychological harm for elephants as to cause some of the few known cases of complex post-traumatic stress disorder in another species (Rizzolo \& Bradshaw 2018).

Recognising elephants as persons means that we are "thinking about human-elephant relations in terms of intersubjective interactions" (Locke 2017). A step in this direction was taken in Sri Lanka in 2014, when an illegally captured baby elephant was discovered and taken into state care for rehabilitation. It was the elephant that was considered the "aggrieved party" in the legal prosecution that followed (Jasinghe \& Fernando 2016).

If elephants are recognised as persons, captive elephants would likely be considered slaves. Some slaves may be better off than others, but all are at the bottom of power relations. Like other slave trades, the tourism industry is interconnected with "an 'organized' wildlife criminal network" which captures wild elephant calves from Protected Areas (Jasinghe \& Fernando 2016). The rehabilitation program outlined by B\&W fits within the broader quest to end slavery and establish just interspecies relations (Crist 2020). Just relations can only be formed when power is shared and equalised (Kopnina 2020). A just elephant-human relation is one where elephants can withhold consent.

Compassionate conservation of human-bonded elephants. Can just relations be formed between humans and elephants? B\&W say "yes". Ending the exploitation of elephants could, after all, also take the form of ending human-elephant relations entirely. B\&W caution that this could cause other forms of injustice. Thus, the rewilding of elephants presents a complex 
ethical question. Compassionate conservationists have adopted four guiding principles to help navigate such dilemmas:

1. Do no harm is a principle adopted from medical bioethics; it is a call to ensure that interventions do not cause more harm than good. The lives of captive elephants are intertwined with humans. Thus, any intervention must attend to the relationship. We agree with B\&W that separating captive elephants from humans risks harming those elephants, the humans that depend on them, and the potential for future reciprocity.

2. Individuals matter is a principle that differentiates compassionate conservation from other conservation traditions. It recognizes the intrinsic value of individuals alongside their species, calling for conservation goals to be guided by compassion for sentient beings. The rewilding of captive elephants, who comprise around half the global population, could promote the recovery of this species and their ecological function and help end the abduction of wild elephants (Jasinghe \& Fernando 2016), while being guided by compassion for the individual elephants and the humans they are bonded to.

3. Inclusivity is compassionate conservation's principle of moral expansiveness. It calls for all life to be included in conservation's moral community regardless of categorisation (e.g., wild vs. captive). Currently, many living beings are invisible to conservation (Wallach et al. 2020b), including human-bonded elephants. By making all elephants visible, B\&W are challenging some of conservation's basic assumptions.

4. Peaceful coexistence is the fourth and last principle. The purpose of conservation is protecting biodiversity; the purpose of compassionate conservation is promoting peaceful coexistence. B\&W are calling for a relation with elephants that is exactly that. As Lainé (2020) explains, the historical meaning of "mahout" is "the art of living and sharing life with elephants."

Toward elephant sovereignty. B\&W help us imagine a world that has abolished elephant slavery and recognised elephant personhood. There will come a time when, thanks to programs such as theirs, there will be no more elephants to rescue. From this vantage point, we can gaze further into the future, and ask what direction could and should a just humanelephant relation take?

We envisage a future - beyond captivity, beyond co-working (Lorimer \& Rahmat 2020), and beyond rewilding - of elephant sovereignty (Donaldson \& Kymlicka 2011; Rizzolo \& Bradshaw 2019). Recognising animal sovereignty means that we acknowledge other animals as peoples whose lives, territories, and ways of life we respect. It is a commitment to multispecies justice (Celermajer 2020).

Conservationists of today speak as guardians for wild Elephas maximus, and ask: "are there enough of them?" Animal welfarists of today speak paternalistically for captive elephants, and ask "are they treated kindly?" Perhaps the mahouts of the future will speak as emissaries for elephant persons, and help us answer: "how do we share our lives with sovereign elephants?" 


\section{References}

Baker, L., and Winkler, R. 2020. Asian elephant rescue, rehabilitation and rewilding. Animal Sentience 28(1).

Crist, E. 2020. Protecting nature, freeing beings. Animal Sentience 28(13).

Donaldson, S., and Kymlicka, W. 2011. Zoopolis: A political theory of animal rights. Oxford University Press.

Jasinghe, S., and Fernando, S. 2016. Wildlife Crime: Legal Prosecution and Experience in Combatting Wildlife Crime in the Illegal Trade of Elephant Calves in Sri Lanka. Elephant Conference, Centre for Ecological Sciences, Indian Institute of Science, Bangalore.

Kopnina, H. 2020. Of elephants and men. Animal Sentience 28(2).

Lainé, N. 2020. Anthropology and conservation. Animal Sentience 28(5).

Locke, P. 2017. Elephants as persons, affective apprenticeship, and fieldwork with nonhuman informants in Nepal. HAU: Journal of Ethnographic Theory 7:353-376.

Lorimer, J., and Rahmat, K. 2020. Elephants at work. Animal Sentience 28(7).

Rizzolo, J. B., and Bradshaw, G. 2019. Nonhuman animal nations: Transforming conservation into wildlife self-determination. Society \& Animals 1:1-21.

Rizzolo, J. B., and Bradshaw, G. A. 2018. Human leisure/elephant breakdown: Impacts of tourism on Asian elephants. In: Carr, N. \& Young, J. (Eds.), Wild animals and leisure. Routledge, pp. 129-147.

Sukumar, R. 1992. The Asian elephant: Ecology and management. Cambridge University Press.

Wallach, A. D., et al. 2020a. Recognizing animal personhood in compassionate conservation. Conservation Biology.

Wallach, A. D., et al. 2020b. When all life counts in conservation. Conservation Biology. 


\section{Call for Papers}

Special Issue of the Lournal of Consciousness Studies

Plant Sentience: Theoretical and Empirical Issues

Guest Editors: Vicente Raja (Rotman Institute of Philosophy, Western University) Miguel Segundo-Ortin (School of Liberal Arts, University of Wollongong)

In this special issue, we address the issue of plant sentience/consciousness from different disciplines that combine both theoretical and empirical perspectives. Some of the questions to be addressed in the special issue include the following:

- Plants exhibit interesting behaviors; does this entail that they are conscious to some extent?

- What are the requirements for a living organism to be conscious? Do plants meet these requirements?

- What does the possibility of plant sentience/consciousness entail for the study of the evolution of consciousness?

- Is it just a categorical mistake to attribute consciousness to plants?

- Can we talk about different levels or degrees of consciousness?

\section{How to submit?}

\section{Deadline: June $\mathbf{1}^{\text {st }}, \mathbf{2 0 2 0}$}

Please submit your papers (max. 9000 words including footnotes, references, abstract, etc.) to vgalian@uwo.ca with subject "Paper Special Issue JCS".

For more information, including bibliography and more detailed descriptions of the topics and questions to be addressed in the papers submitted to the special issue, please contact the guest editors at vgalian@uwo.ca (Vicente) or mso693@uowmail.edu.au (Miguel). 